\title{
RESEARCH OF WEAR RESISTANCE OF CHROME DIAMOND COATING
}

\author{
Julia AVERINA ${ }^{1}$, Galina KALYAKINA ${ }^{1}$, Veniamin BOLDYREV², Alexander CHEREDNICHENKO³, \\ Evgenia RYBINA ${ }^{1}$
}

${ }^{1}$ Russian University of Chemical Technology D.I. Mendeleev, 125047, Russia, Moscow, Miusskaya pl., 9 , averinajm@mail.ru

${ }^{2}$ Moscow State Technical University. N.E. Bauman, 105005, Russia, Moscow, 2nd Baumanskaya St., 5, building 1, veniamin bk@mail.ru

${ }^{3}$ Peoples' Friendship University of Russia, 117198, Russia, Moscow, Miklouho-Maclay St., 6, sorbotek@yandex.ru

https://doi.org/10.37904/metal.2020.3556

\begin{abstract}
Chrome plating is widely used as a protective and decorative coating and to increase the wear resistance of measuring and cutting tools. To improve the properties of the chrome coating, nanosized particles are coprecipitated with it. Since nanodiamond particles possess the properties of diamond, that is, superhardness, low coefficient of friction, high thermal conductivity and chemical inertness, they are used precisely during deposition with chromium. This article presents a study of chromium-diamond coating. Determination of its wear resistance, microhardness, porosity and other indicators. The use of chromium-diamond coating allows to improve to a greater extent the physicomechanical indices of hard chromium plating, as well as to increase corrosion resistance and increase the service life of parts operating under conditions of corrosion wear.
\end{abstract}

Keywords: Chrome plating, chrome-diamond coating, wear resistance, wear of the coating

\section{INTRODUCTION}

Chrome is a metal of steel color with a bluish tint. Valuable physical properties are the beautiful decorative appearance of chrome, a stable luster that does not fade with time, good reflectivity, heat resistance and nonoxidation at high temperatures. Depending on the deposition mode, chromium coatings change their hardness in the range from 300 to $1000 \mathrm{kgf} / \mathrm{mm}^{2}$. The friction coefficient of chrome coatings is lower than that of steel, and the wear resistance is several times higher, especially when using porous-chrome coatings. Chrome plating has been widely used as a protective and decorative coating, and nickel and copper coatings are used as sublayers [1].

Of all types of electroplating coatings, chromium plating, in its peculiar conditions for the deposition of chromium, occupies a special place. First of all, it should be noted the features of preparation for chromium plating. Chrome electrolyte, being a strong oxidizing agent, has a destructive effect on many materials of organic origin. Meanwhile, when chrome plating, there is always a need for special control over the process and disposal of chromium waste [2,3].

Today, the urgent task all over the world is to create such hardening coatings that could combine such qualities as high wear resistance under abrasive wear and friction units, a relatively low friction coefficient, high corrosion resistance, manufacturability, relatively low cost and the very The main thing is less impact on the environment. To solve a wide variety of technical problems, hard chrome plating was widely used. However, the technology of nanodiamond chrome plating can significantly improve the physical and mechanical properties of hard chromium plating. Nanodiamond chrome coating significantly exceeds the known and widely used in a wide variety of production cycles hard chromium plating, which can significantly improve the technical 
characteristics of coatings, as well as significantly expand the scope of application of nanodiamond chrome plating. Nanodiamond chrome coating is characterized by increased hardness, wear resistance, corrosion resistance, low coefficient of friction and provides an increase in the service life of the tool and parts of friction units by 2-15 times [4].

\section{EXPERIMENTAL}

Studies have shown that chromium-diamond coating is superior to conventional chromium plating with hexavalent chromium. Studies were conducted on porosity, microhardness, wear resistance and gloss.

The coating thicknesses of the samples used for the studies were accurately determined using an OLYMPUS LEXT OLS4100 confocal laser scanning microscope and are shown in Table 1.

Table 1 Sample coating thicknesses

\begin{tabular}{|c|c|}
\hline Sample, № & $\begin{array}{c}\text { The measured coating } \\
\text { thickness (microns) }\end{array}$ \\
\hline 1 & 11.852 \\
\hline 2 & 22.020 \\
\hline 3 & 46.340 \\
\hline
\end{tabular}

To determine the porosity, the method of applying filter paper was used. Filter paper was immersed in a measuring cup with solution 32 (solution 32 consists of potassium iron-hydrogen- $3 \mathrm{~g} / \mathrm{dm}^{3}$; sodium chloride- 10 $\left.\mathrm{g} / \mathrm{dm}^{3}\right)$, then applied to the sample so that there was no air gap between the paper and the sample. Then, after 5 minutes, the paper was removed from the sample, washed with distilled water and, placed on a clean glass, dried [5].

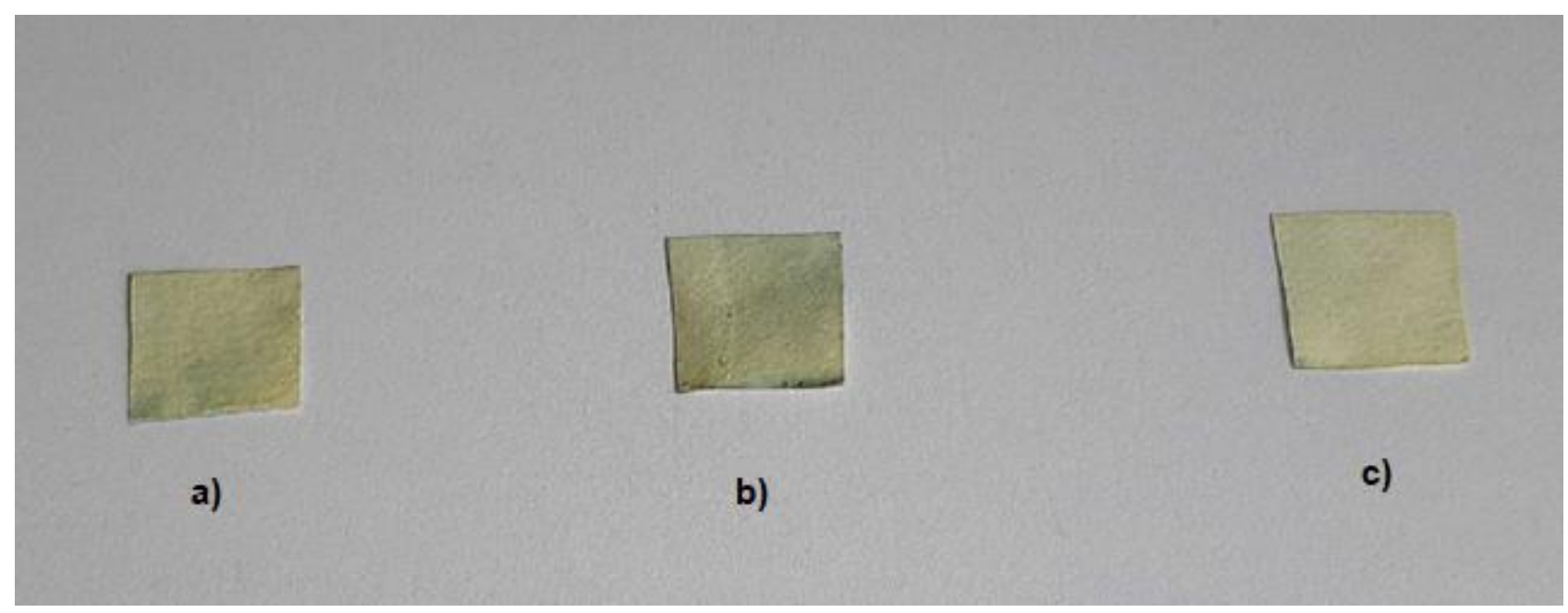

Figure 1 The presence of pores in three samples: a) sample № 1, b) sample № 2, c) sample № 3

Thus, in Figure 1 it can be seen that the coating has absolutely no pores, since no blue dots were detected. This suggests that the coating has high corrosion resistance, since the corrosive medium does not reach the steel base.

Microhardness is the hardness of individual sections of the microstructure of a material. The most widely used method of measuring microhardness by pressing a pyramid with a small load into the sample. This method is also called the Vickers method (Figure 2), a tetrahedral diamond pyramid with an apex angle of $136^{\circ}$ is pressed into the sample. Hardness shows the area of the impression from the pyramid. 


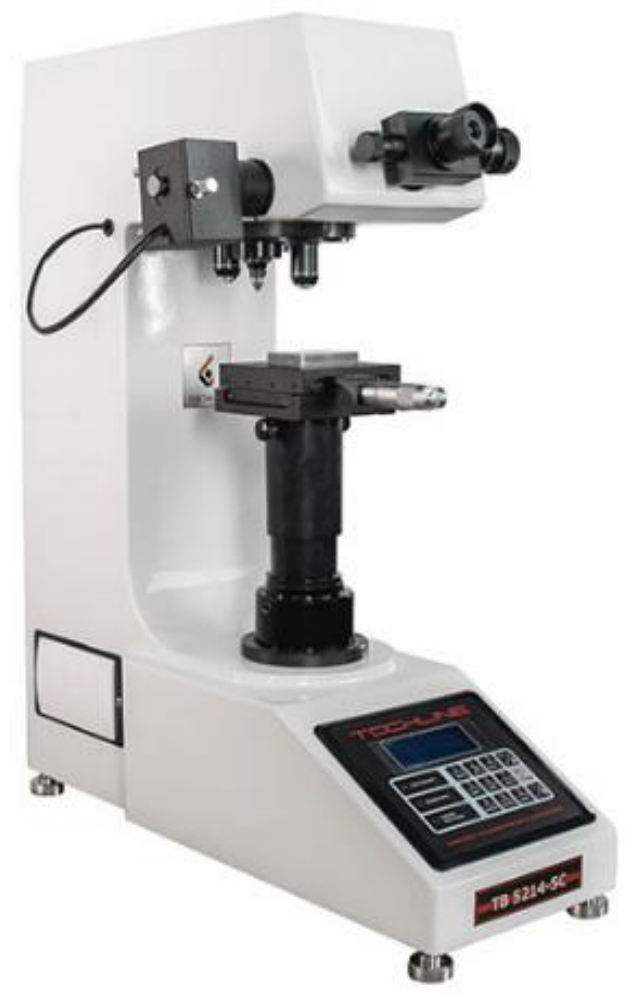

Figure 2 Vickers hardness tester

The measurement is carried out as follows: set the test sample coated on a stage and select a place for printing, then release the screw and gently turn the stage counterclockwise until it stops, avoiding jolts when approaching the stop, fasten the table in this position by slow rotation the handles counterclockwise lower the stem so that the diamond tip touches the surface of the test sample, the handle is rotated about $180^{\circ}$ and held for $10-15$ seconds, after exposure to a load $(0.5 \mathrm{~kg})$, turn the handle to its original position, then release the screw and very carefully turn the object table to its previous position until it stops, measure the control parameter of the print using a photoelectric ocular micrometer, calculate the microhardness of the coating according to the formula (1).

$H V=\frac{P}{S}=0.19 \frac{P}{d^{2}}$

where:

$P$ - is the load on the pyramid (kgf)

$S$ - is the imprint area of the tetrahedral pyramid with an angle at the apex of $136^{\circ}$

$\mathrm{D}$ - is the arithmetic average of the length of both diagonals of the print after unloading $(\mathrm{mm})$ [5].

The results obtained by this method are shown in Table 2 .

Table 2 Microhardness values obtained by the Vickers method

\begin{tabular}{|c|c|}
\hline Sample, № & HV0.2 (MPa) \\
\hline 1 & 328.4 \\
\hline 2 & 318.9 \\
\hline 3 & - \\
\hline
\end{tabular}


The microhardness of sample No. 3 cannot be measured by this method, since the coating thickness is too large, more than 2 times the thickness of the coating of sample No. 2. According to the data of the first two samples, it is clear that the order of the data obtained is one. And based on the data obtained in [4], the microhardness can reach $1000 \mathrm{MPa}$, the results we obtained are very worthy.

Wear resistance is the property of materials to resist wear due to friction. It is one of the most important characteristics of coatings and materials, since it can be used to extend the life of some parts. A study on wear resistance will be carried out using a Taber rotational abrasimeter.

A sample was placed on a rotating pad, abrasive wheels were lowered onto the sample, which abrasive with a load of $500 \mathrm{~g}$ and a speed of $60 \mathrm{rpm}$ for 5000 cycles. The results of the tests are shown in Table 3 [6].

Table 3 The obtained weight loss values of the samples

\begin{tabular}{|c|c|c|c|c|}
\hline Sample, № & $\mathbf{m}_{\text {to }}(\mathbf{m g})$ & $\mathbf{m}_{\text {after }}(\mathbf{m g})$ & $\mathbf{W t}_{\text {loss }}(\mathbf{m g})$ & Degree of wear \\
\hline 1 & 90810 & 90770 & 40 & 8 \\
\hline 2 & 92550 & 92520 & 30 & 6 \\
\hline 3 & 95100 & 95060 & 40 & 8 \\
\hline
\end{tabular}

The wear rate or Taber wear ratio was obtained as the difference in weight loss per 1000 cycles of abrasion during the test. The lower the degree of wear, the better the abrasion resistance of the material. From the data obtained, we see that the order of the wear coefficient is one, therefore, the wear resistance of samples with different coating thicknesses is approximately the same.

Gloss is one of the standard parameters for assessing the appearance of a coating. There are special instruments for determining the degree of gloss of a coating; they operate on the principle of measuring the reflection coefficient of a light beam. Depending on the degree of gloss, a certain geometry of the device is used (angle of definition of gloss):

- $20^{\circ}$ - for surfaces with a mirror sheen (plastics, varnish, glossy paper, metal, painted metal);

- $45^{\circ}$ - for medium and high gloss surfaces;

- $60^{\circ}$ - universal, most used for foreign coatings and plastics (paint coatings, anodized aluminum, ceramics);

- $75^{\circ}$ - for low-gloss surfaces (vinyl, polymer films, etc.);

- $85^{\circ}$ - for testing surfaces with a very low degree of gloss - paper, textured plastic, soft touch varnishes, etc. (aviation, accessories, car interior).

For a numerical assessment of the magnitude of gloss, the appropriate scale of GU (Gloss Unit - gloss units) and reference points are used. $0 \mathrm{GU}$ corresponds to a matte surface with zero reflection, and the maximum GU value corresponds to a glossy black surface.

The gloss meter is placed perpendicular to the sample and the button is pressed, the result appears on the display. Since a visual assessment, I found that the coating is shiny, the angle at which I took the values is $20^{\circ}$. The measurements were carried out to three converging results, then the arithmetic average was found, the final data are presented in Table 4 [7].

Table 4 The resulting gloss values

\begin{tabular}{|c|c|}
\hline Sample, № & Gloss value (GU) \\
\hline 1 & 62 \\
\hline 2 & 67 \\
\hline 3 & 74 \\
\hline
\end{tabular}


From the obtained data, we see that the values of the gloss increase slightly with increasing coating thickness, but in general they are in the same order. The value of the degree of gloss to a greater extent depends on the roughness, from this we can conclude that the roughness of the coating is not large.

\section{CONCLUSION}

Thus, from the conducted studies, we can conclude that this coating is non-porous, has good hardness and wear resistance, and is not inferior to shiny chrome in the degree of gloss. And all this with a coating thickness of 10 microns, therefore, it can replace some types of chromium plating.

\section{ACKNOWLEDGEMENTS}

The work was carried out with the funding of the D. I. Mendeleev RSTU, VIG no. X-2020-011.

\section{REFERENCES}

[1] AMPOLSKY A. M. Galvanotechnics. Moscow-Leningrad: Mashgiz, 1952.

[2] BOGORAD L. YA. Chrome plating. Leningrad.: Engineering, 1984.

[3] AVERINA, YU. M., KALYAKINA, G. E., MENSHIKOV, V. V., KAPUSTIN YU.I., BOLDYREV V.S. Designing processes for the neutralization of chromium and cyanide-containing wastewater by the example of galvanic production. Vestnik MGTU im. N.E. Bauman. Series Natural Sciences. 2019, no. 3, pp. 70-80.

[4] DOLMATOV V. Yu., BURKAT G.K., MYLLYMÄKI V., VEHANEN A. Electrochemical chromium-diamond coating. Superhard materials. 2015, No. 2, C. 21-45.

[5] GOST 9.302-88. Metallic and non-metallic inorganic coatings. Control methods, 1988.

[6] ABRASHOV A. A., GRIGORYAN N. S., VAGRAMYAN T. A., SMIRNOV K. N. Methods of control and testing of electrochemical and conversion coatings. Moscow: RCTU them. D.I. Mendeleev, 2016.

[7] ABRASHOV A. A., ZHELUDKOVA E. A, GRIGORYAN N. S., VAGRAMYAN T. A. Methods for testing coatings. Laboratory workshop. Moscow: RCTU them. D.I. Mendeleev, 2018. 